\title{
Analysis of Electricity Consumption and Business Model of Demand Side Management in Energy Internet
}

\author{
Zhigong Wu and Yunhu Wang* \\ School of Economics and Management, North China Electric Power University, Beijing 102206, China \\ Email: 13902286788@126.com, yunhuwang@126.com*
}

\begin{abstract}
In order to explore the electricity consumption and business model of demand side management (DSM) in energy Internet, first of all, it is necessary to analyze the intelligent electricity consumption and DSM. Secondly, the construction elements of DSM business model are described from four aspects, user screening, user incentive scheme, intelligent interactive terminal, and user interactive power platform. Finally, DSM business model is elaborated, and three kinds of services are introduced, including distributed energy service, user energy efficiency service, and electric vehicle operation management service. The results show that the business model of DSM can provide better services for users. It can be seen that the DSM model has good effect in energy Internet.
\end{abstract}

Keyword: Energy Internet, electricity consumption demand, DSM business model

\section{Introduction}

In the development of China's power system, energy Internet has become an important form, which will change the existing forms of energy utilization and affect the management mode [1]. Based on the perspective of electricity consumption and demand side management (DSM), the utilization of energy under the condition of Internet is analyzed, and business model emerges in electricity consumption and DSM. Based on the interaction between power grid and users, the controllable load part should be analyzed to promote the development of energy Internet, focusing on the communication between users and power grid, and access to other forms of power generation $[2,3]$.

With the development of economy and technology, electric vehicles and distributed energy have emerged. Intelligence has become an indispensable part of people's daily life. From another point of view, the continuous improvement of intelligent conditions also shows that people's demand for electricity has gradually exceeded the basic daily standards, and has better requirements for its reliability and quality level [4].

After the emergence of smart grid, the biggest difference between smart grid and traditional grid is the need to support interactive user service and demand side response. Smart grid is better at encouraging users to participate in grid interaction, ensuring better operation and control of the grid, and improving the customer service level of power suppliers. In addition, the emergence of intelligent power technology can also expand the breadth of user services, and help power suppliers to create a sound business model with user value as the center $[5,6]$.

Users have begun to attach importance to the concept of energy conservation, so as to have more choices in their daily life. This new business, new user form and new demand all promote the change of this business model, and at the same time, it needs perfect technical support. After this transformation, traditional power grid enterprises can establish service-centered concept to meet the personalized needs of users in terms of service scope, form and promote the development of business model as a new technical support $[7,8]$.

\section{Analysis of Intelligent Electricity Consumption and DSM}

Under the mode of energy Internet, the power network is more flexible, which can realize the integration of power flow and information flow, and realize the DSM scheme on the same platform. This new management strategy needs the physical foundation provided by the platform, and chooses to control the situation. In practice, most of them are direct load control. After power supply enterprises reach power 
supply agreement with users and factories, power supply departments can control users and user equipment remotely. The following figure shows the electricity demand of different industries in 2016.

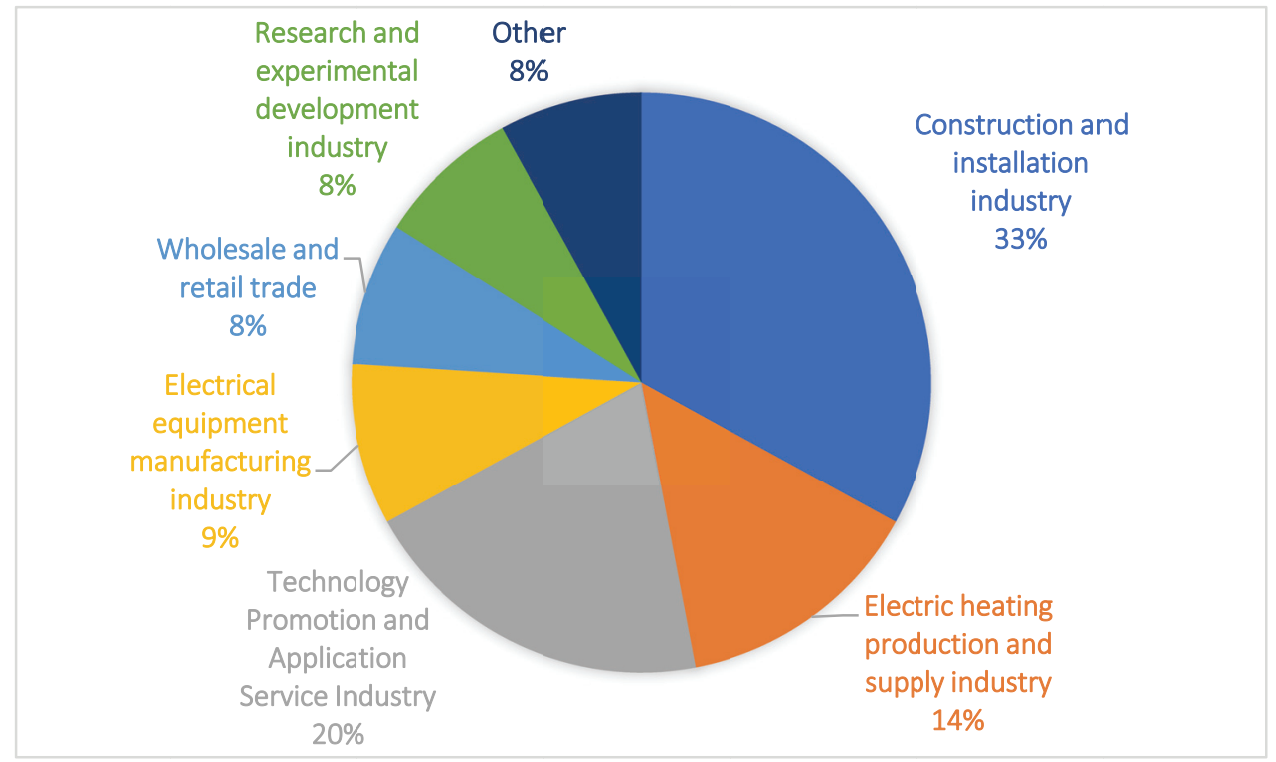

Figure 1. The main distribution sources of domestic electricity sales companies

\section{Constructive Elements of DSM Business Model}

\subsection{User Screening}

There are a certain number of users having the ability to adjust load demand. The load involved in demand response should have the characteristics of large power consumption, flexible power consumption time, and adjustable power consumption load like household water heaters, central air conditioning, municipal water pumps, etc. Users can be screened through questionnaire on users with large electricity consumption.

\subsection{User Incentive Scheme}

A reasonable user incentive scheme can be chosen through economic means to achieve the goal of demand, so that users can actively participate in the interaction. Its process has flexible tariff policy and can directly utilize time-sharing tariff. For example, peak and valley can adopt incentive pricing, determine their contribution according to the amount of electricity users, and compensate after a certain period of time and return to users.

If the user receives the terminal incentive signal generated by the node, he can select the storage value or other management forms to adjust reasonably according to his own needs. In system operation, photovoltaic controllers can better cope with the peak power consumption by automatically adjusting power response incentive information of high-power equipment. Considering many difficulties in the formulation and implementation of dynamic time pricing, such as auditing by management agencies or user risks in the process, incentive signals can be generated from the perspective of implementers by combining the objectives of different nodes. The contribution degree obtained by users during peak period can be returned to users, which can achieve the effect of implementing electricity price adjustment. There are differences before and after the reform in power supply, power generation, distribution, electricity sales and other processes, and it will be explained in detail below. 

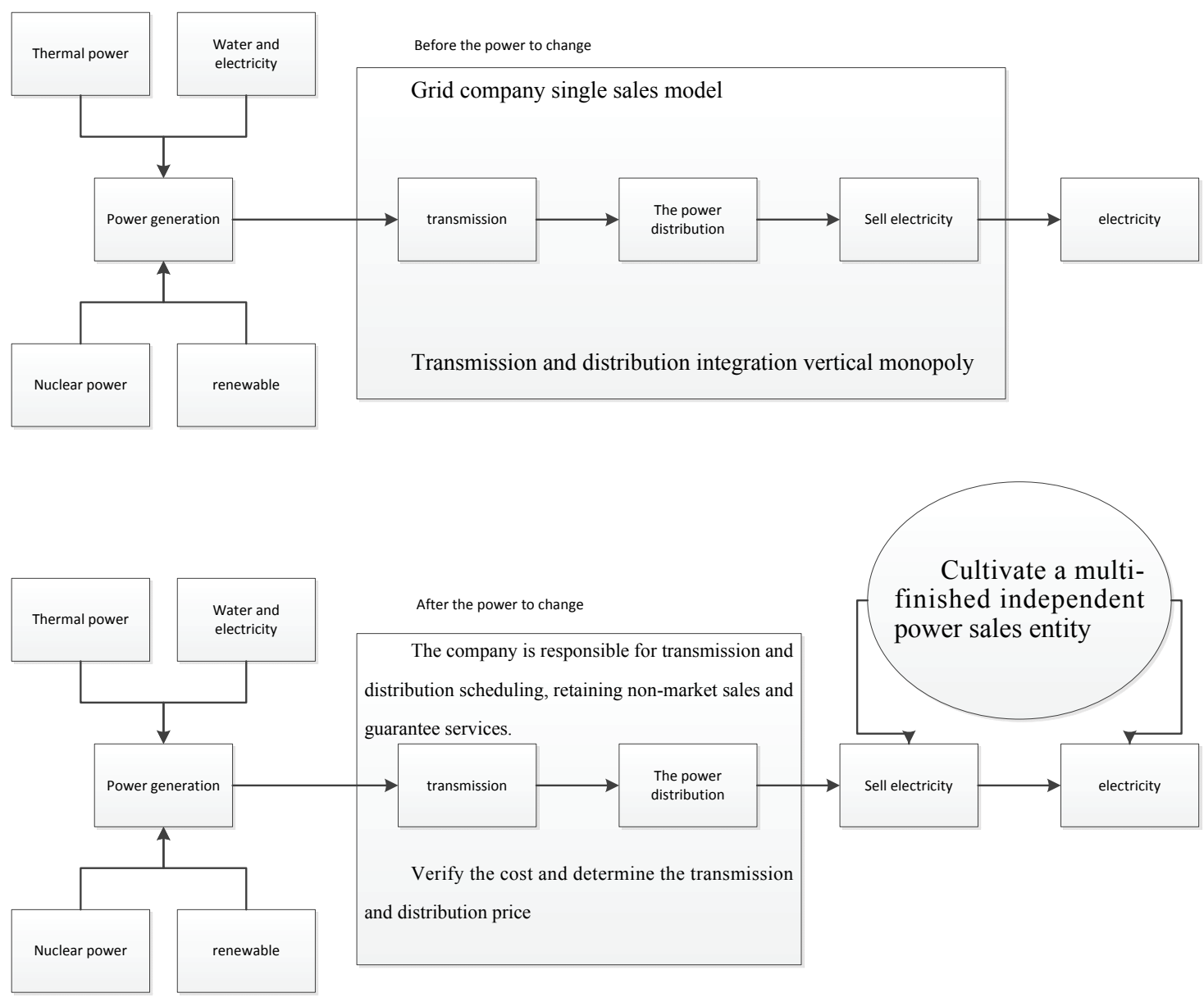

Figure 2. Changes in electricity sales mode before and after electricity reform

Table 1. Statistics of the whole society's electricity consumption data in 2016

\begin{tabular}{lcc}
\hline Name of index & $\begin{array}{c}\text { Absolute quantity } \\
\text { (Unit: 100 million kWh) }\end{array}$ & $\begin{array}{c}\text { Year-on-year } \\
\text { growth (\%) }\end{array}$ \\
\hline Domestic electricity consumption for the whole society & 59182 & 5.0 \\
Primary industry electricity consumption & 1075 & 5.2 \\
Electricity consumption in secondary industry & 42108 & 2.9 \\
Industrial electricity consumption & 7015 & 4.4 \\
Electricity consumption in heavy industry & 34367 & 2.5 \\
Electricity consumption in tertiary industry & 7951 & 11.2 \\
Domestic electricity consumption of urban and rural residents & 8055 & 10.8 \\
\hline
\end{tabular}

\subsection{Intelligent Interactive Terminal}

Intelligent interactive terminals with policy configuration and signal interaction functions can automatically form optimal operation schemes according to user-defined strategies and incentive signals. Intelligent interactive terminal is mainly designed to facilitate users to intuitively understand the power consumption information, which is installed in the user's home. It interacts data through micro-power wireless data and the collector, and displays household power consumption information, such as real-time power and total power consumption; it can interact with the main station to facilitate the exchange of information between power departments and users. When the electricity consumption of users reaches the second and third levels, the display screen will have obvious sound and light prompts to users, so that users 
can get a full understanding of their electricity consumption. Table 1 shows the absolute electricity consumption of different industries in 2016, as well as the year-on-year growth, which is convenient for comparison and statistics.

\subsection{User Interactive Power Platform}

This platform can provide users with an online power portal, achieve access between terminals through personal computers, tablets, mobile phones and other ports, and achieve functional applications through electricity statistics, or electricity recommendations. There are three main aspects: one is energy efficiency analysis. According to the collected data, combined with statistical algorithm, the electricity consumption situation is identified, so as to provide reasonable telephone service for users. The second is user participation. It is necessary to use multiple ways to transmit users' energy reports, better record the situation of electrical equipment, and increase the use of electricity habits, so as to have targeted energy-saving recommendations. The third is the user. As the center of user interaction, users can not only provide energy utilization information and energy-saving suggestions, but also track energy efficiency and carbon footprint and share them through social networks.

\section{$4 \quad$ DSM Business Model}

\subsection{Distributed Energy Services}

It is mainly reflected in providing access, operation, maintenance and other full-service services for the increasing number of distributed energy customers. It specifically includes: First, the expected benefits of distributed energy assessment. The construction of distributed energy should achieve a win-win situation between power grid and users, so the power supply bureau can evaluate the expected benefits of users and encourage users to build distributed energy. Second, provide all-round service support and corresponding business management from construction, access to operation and maintenance for various forms of distributed energy, such as photovoltaic, energy storage, small wind power, micro-gas turbine, etc. Third, support the optimal operation of distributed energy, including distributed energy generation power forecasting and energy storage optimal scheduling. In addition, it is necessary to grasp the threat from the outside world and do distribution planning well. The specific content is shown in the following figure.

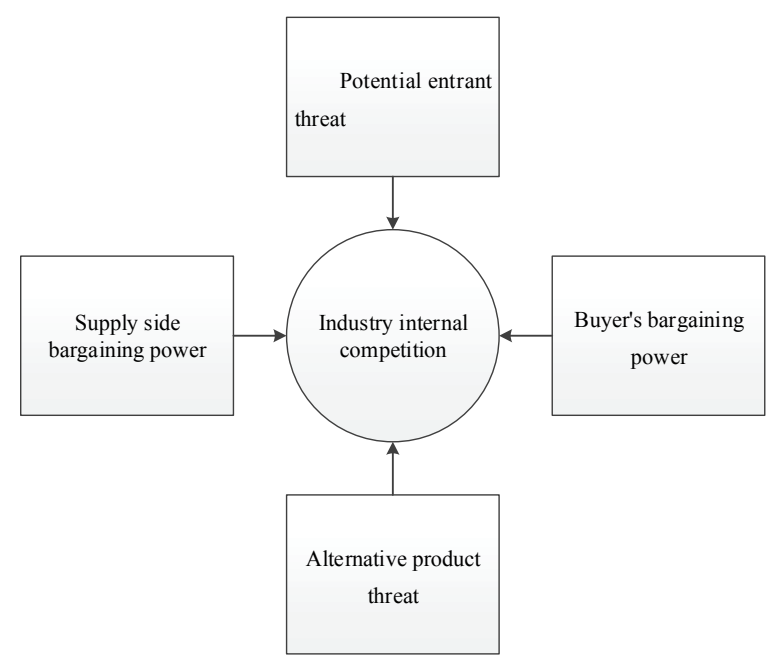

Figure 3. Porter five-force model

\subsection{User Energy Efficiency Service}

User energy efficiency services provide users with energy-saving analysis and intelligent evaluation, realize energy-saving-oriented intelligent two-way interactive user management and service system, improve the 
level of intelligence and interaction of energy services, in order to achieve the goal of demand-side energy efficiency management.

\subsection{Electric Vehicle Operation Management Service}

In the operation and management of electric vehicles, the core is the charging network between electric vehicle users and electric vehicles, so as to better reflect the following functions. Firstly, the integration of multiple applications is realized through interoperability and efficient business processing. According to different sources, it is supposed to grasp the form of information sharing and interaction, and carry out reasonable cost calculation and settlement in necessary supervision. The second is to realize advanced intelligent optimization analysis and provide advanced intelligent optimization analysis function for different users. For example, charging station operators can determine the optimal charging arrangement and price through battery usage, charging time, and driving time of electric vehicles. Load forecasting is based on time and location, and renewable energy load is integrated to achieve more effective and optimized load control management at peak charging time. Finally, through one-stop integration mode, the cost of use is reduced. According to the specific needs of users, provide a series of customized services, such as the use of advanced analysis optimization technology to optimize the charging and replacement of electric vehicles. Through asset management services, monitor the health status of charging equipment.

\section{Conclusion}

Intelligent community and intelligent building are the important components and manifestations of power consumption in smart distribution network. They are also the embodiment of power consumption under the energy Internet. The business model of DSM is to realize real-time interactive response between power grid and users, to enhance the comprehensive service capability of power grid, to meet interactive marketing needs, and to improve service level. This is also the carrier to realize energy service and enhance user experience in smart distribution network.

Through the construction of intelligent buildings, it can better show the advantages of the intelligent distribution network to users, such as economy, efficiency, energy saving and environmental protection, provide users with all-round information interaction function, change their way of life, and enhance the comfort and convenience of work and life. In the energy supply, it can provide better services for users, and from the service and cost, it can reflect its intelligence and the development of business models.

\section{Reference}

1. Sun, Yi, et al. "Interactive Evaluation Model for Residential Electricity in Demand Side Management." Automation of Electric Power Systems 41.13(2017): 62-69.

2. Khanna, Nina Zheng, G. Jin, and X. Zheng. "Effects of demand side management on Chinese household electricity consumption: Empirical findings from Chinese household survey." Energy Policy 95(2016): 113-125.

3. Iwafune, Yumiko, and Y. Yagita. "High-resolution determinant analysis of Japanese residential electricity consumption using home energy management system data." Energy \& Buildings 116(2016): 274-284.

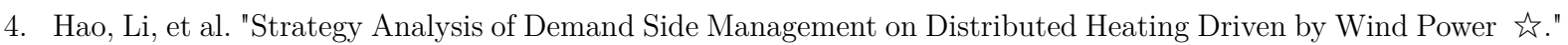
Energy Procedia 105(2017): 2207-2213.

5. Chou, Ding Chin, C. S. Chang, and Y. Z. Hsu. "Investigation and analysis of power consumption in convenience stores in Taiwan." Energy \& Buildings 133(2016): 670-687.

6. Salahuddin, Mohammad, and K. Alam. "Information and Communication Technology, electricity consumption and economic growth in OECD countries: A panel data analysis." International Journal of Electrical Power \& Energy Systems 76(2016): 185-193.

7. Broadstock, David C., J. Li, and D. Zhang. "Efficiency snakes and energy ladders: A (meta-)frontier demand analysis of electricity consumption efficiency in Chinese households." Energy Policy 91(2016): 383-396.

8. Sossan, Fabrizio, et al. "Grey-box modelling of a household refrigeration unit using time series data in application to demand side management." Sustainable Energy Grids \& Networks 5.6(2016): 1-12. 